\title{
Is Commitment Getting Infected Too? \\ How COVID-19 Stay-Home Orders Influence Workgroup Commitment
}

\author{
Daniel H. Stein \\ daniel_stein@haas.berkeley.edu \\ Jennifer A. Chatman \\ chatman@berkeley.edu \\ Juliana Schroeder \\ jschroeder@haas.berkeley.edu \\ Haas School of Business \\ University of California, Berkeley \\ 545 Student Services Building \\ Berkeley, CA 94720-1900
}

Version Date: January 30, 2021

\begin{abstract}
Author Note: This manuscript is currently undergoing peer review and is not the authoritative document of record. Comments are welcome. All of our data, code, and survey materials are available in the Open Science Framework (OSF) repository for this project (https://osf.io/g6nua/?view_only=f79a6b5037ad49378ca986675a1bbd1b).
\end{abstract}




\begin{abstract}
The COVID-19 pandemic and associated "Stay-Home" restrictions in the United States have disrupted employees' lives. We leverage the change brought on by the Stay-Home restrictions to examine corresponding changes in employees' commitment to their workgroup. Specifically, we advance and test a model predicting that the Stay-Home restrictions prevented workgroups from engaging in rigidly performed, meaningful workplace activities (i.e., ritualistic workplace activities), which subsequently made members feel that the group was less cohesive and ultimately reduced members' workgroup commitment. We also compare changes in workgroup commitment to changes in workgroup identification, hypothesizing that commitment to one's group erodes more than identification when workgroups are perceived to be less cohesive. We test our model in a four-wave panel survey of 772 U.S. employees at the onset of the Stay-Home restrictions, which allows us to examine within-person changes to commitment over time. Consistent with our hypotheses, commitment decreased as the duration of Stay-Home restrictions increased, which was mediated by corresponding declines in engaging in ritualistic workplace activities and perceptions of the workgroup's cohesiveness. Further, commitment to one's workgroup declined more than did identification with the workgroup, due to the stronger relationship between perceived group cohesion and commitment (vs. identification). We replicated these results in a separate, preregistered cross-sectional survey. Our findings shed light on the mechanisms underlying workgroup commitment, demonstrating that engagement in ritualistic activities, which enhance workgroup cohesion, is linked to stronger commitmentmore so than identification-over time.
\end{abstract} Keywords: commitment; identification; group; ritual; COVID-19 


\section{Is Commitment Getting Infected Too? How COVID-19 Stay-Home Orders Influence Workgroup Commitment}

The coronavirus (COVID-19) pandemic has brought fast-moving and vast changes to the employee experience. By April 2020, more than 95\% of the U.S. population was urged to stay home via government issued "Stay-Home" orders. ${ }^{1}$ We investigate how this unprecedented disruption influenced employees' commitment to their workgroups - that is, the degree that employees have a volitional psychological bond that reflects their dedication to and responsibility for a workgroup (Klein et al., 2012). ${ }^{2}$ Understanding how the Stay-Home orderswhich were designed to slow the spread of COVID-19-influenced employees' commitment is important because commitment is linked to a range of positive employee outcomes including performance, retention, and well-being (e.g., Becker, 1992; O'Reilly \& Chatman, 1986).

We advance a model to understand how the Stay-Home orders influenced employee workgroup commitment and test the model in a longitudinal survey of working Americans during the early stages of the Stay-Home orders in the U.S. (April to June 2020). We theorize that meaningful behavioral investments that employees make at work, which we operationalize as workplace activities that are performed rigidly and are perceived as meaningful (i.e., ritualistic workplace activities; Hobson et al., 2018), influence perceptions that the workgroup is cohesive, and that group cohesion subsequently affects commitment. As a result, we propose that, because the Stay-Home orders often prevented workgroups from engaging in the ritualistic workplace activities that existed before these restrictions were in place, employees will perceive their workgroups as less cohesive and consequently feel less committed to their workgroups as

\footnotetext{
${ }^{1}$ https://web.archive.org/web/20200406005340/https://www.nytimes.com/interactive/2020/us/coronavirus-stay-athome-order.html

${ }^{2}$ We used Klein et al.'s (2012) unidimensional commitment conceptualization because it was designed to be applicable to multiple foci (including workgroup commitment) and it supported our focus on commitment as a psychological bond rather than a purely instrumental one (e.g., Caldwell et al., 1990).
} 
the duration of Stay-Home orders lengthened. We further hypothesize that commitment, compared to workgroup identification — the extent to which an individual defines themselves in terms of their membership in a particular workgroup (Ashforth \& Mael, 1989)—will be more contingent on ongoing behavioral demonstrations such as the degree to which members are behaviorally linked (i.e., perceived workgroup cohesiveness), rather than on how a person defines his or her own self-concept and relates it to the group. As such, commitment will erode more than identification will at the onset of the Stay-Home orders, because (1) the Stay-Home orders hindered the ability of workgroups to engage in ritualistic workplace activities, ${ }^{3}$ resulting in lower levels of perceived cohesiveness, and (2) the perceived cohesiveness of the workgroup influences commitment to-more than identification with—one's workgroup, because identification is less dependent on continuing behavioral investments, such as engagement in ritualistic activities and the ensuing group cohesion.

This research makes four key contributions. First, we advance theories of workgroup commitment, suggesting that commitment may be less stable than previously theorized (e.g., Solinger et al., 2008), and contingent on members' ongoing behavioral investments (Becker, 1960). To derive this insight, our study contains four waves of data collection, investigating within-person changes in commitment rather than the more typical focus on between-person differences using cross-sectional designs (Bergman \& Jean, 2016). Second, our research leverages a catastrophic event, the COVID-19 pandemic, as a useful empirical referent (Smith, 1977) enabling us to surface the essential features of commitment and sharpen the distinction between workgroup commitment and identification (van Dick, 2016). Specifically, we show that commitment and identification erode at different rates and are, as such, likely fueled by different

\footnotetext{
${ }^{3}$ Although rituals can develop virtually and not just in-person, many organizations had in-person rituals that the Stay-Home orders disrupted. We seek to study the disruption of those rituals and the relevant consequences.
} 
mechanisms. Third, by drawing from sociological and psychological theory, we consider ritualistic workplace activities and resulting group cohesion as novel mechanisms that explain why workgroup commitment may decline after a significant change in work conditions brought on by an exogenous shock (Stay-Home orders). Finally, we identify a key managerial implication, which is that workgroups aspiring to maintain high levels of commitment should develop rituals that can be meaningfully accomplished.

\section{COVID-19 Orders, Workplace Activities, Workgroup Cohesion, and Commitment}

Due to the rapid spread and virulence of COVID-19, local and state governments in the U.S. limited the number of people who could gather together in-person starting in late March 2020. The resulting "Stay-Home" orders — which were designed to slow the spread of the virushad the additional effect of preventing workgroups from engaging in typical activities together and, in many cases, required them to conduct work remotely (e.g., Kniffin et al. 2021; Van Bavel et al., 2020). Building on prior theorizing that situational factors influence the development of commitment through cognitive and affective evaluations (Klein et al., 2012; O'Reilly \& Chatman, 1986), we examine how Stay-Home orders altered the types of activities in which workgroups engaged and how this changed members' perceptions of their workgroup, and, ultimately, their commitment. We examine workgroups as the focus of commitment because employees are likely to interact with workgroup members on a daily basis, increasing the immediacy and salience of the changes in workgroup interaction induced by Stay-Home orders (Riketta \& van Dick, 2005).

The Stay-Home orders, which required most employees to socially distance, disrupted certain types of group activities more than others. In particular, activities that occur more routinely and with fixed, rigid procedures that are seen as meaningful to employees, were 
especially likely to be disrupted. Consider, for instance, social events like weekly "happy hours" among workgroups, certain ways of enacting meetings to make them more structured and enjoyable, or specific celebrations for workplace achievements like promotion ceremonies; all are all activities that needed to be significantly adapted in the context of Stay-Home orders. Prior research has operationalized the structure and meaningfulness of activities as the degree to which the activity is ritualistic (e.g., Norton \& Gino, 2014; Stein et al., 2021).

We build on previous research to conceptualize workplace activities as being more ritualistic when they have specific physical features (rigid, repetitive actions) as well as psychological features (a sense of meaning; Hobson et al., 2018). Activities can range in how ritualistic they are. For example, even a simple work meeting can be made more ritualistic if it has the physical features of a ritual — such as saying a company motto at the start of a meetingand the psychological features of a ritual—such as affirming different values of the group. ${ }^{4}$ Ritualistic activities rely on rigid adherence to performing sequenced actions (Boyer \& Liénard, 2020). Thus, when major exogenous shocks impact contact, it disrupts the group's ability to adhere to each of the actions in the sequence. We therefore predict that employees' propensity to engage in workgroup rituals will decline at the early stages of Stay-Home orders.

Hypothesis 1: Employees' engagement in ritualistic workplace activities will decrease as the COVID-19 Stay-Home orders continue to be in effect over time.

In considering the potential consequences of disrupting ritualistic workplace activities, we propose that engaging in ritualistic activities may be linked to people's perceptions that their workgroups are cohesive, or bonded together as a group (Hamilton et al., 2002). The more groups engage intimately with one another, share common values, goals, and rules, and feel

\footnotetext{
${ }^{4}$ One example is the Walmart Cheer. Walmart employees sing the structured chant three times a day and the chant ends with an affirmation of one of Walmart's core values ("Who's number one? The Customer!"; Bergdahl, 2004).
} 
emotionally close to one another, the more cohesive members perceive the group (e.g., Campbell, 1958; Yzerbyt et al., 2004). Engaging in ritualistic activities may promote perceptions of group cohesion because ritualistic activities foster salient, visible manifestations of the group's values. In this way, ritualistic activities serve to promote, protect, and perpetuate group members' shared values (Stein et al., 2021). These shared values foster feelings of similarity and intimacy, enabling group members to engage in similar behaviors and feel close (Chatman \& O’Reilly, 2016). Because ritualistic activities promote a shared value system, we propose that engaging in more ritualistic workplace activities will enhance members' perceptions that the workgroup is cohesive. Consistent with this reasoning, external observers view groups with more established rituals as more cohesive (e.g., Lakens, 2010; Watson-Jones \& Legare, 2016), although prior research has not examined whether engaging in ritualistic activities influences members' own perceptions of their group's cohesiveness, as we suggest here.

Hypothesis 2: Engaging in ritualistic workplace activities is positively associated with workgroup members' perception that their workgroup is more cohesive.

We propose that perceptions of workgroup cohesion can positively influence workgroup commitment because cohesive groups are more effectively able to mobilize resources to influence individual outcomes. Thus, more cohesive groups are able to reward committed group members, promoting commitment through social exchange (e.g., Zaccaro \& Dobbins, 1989).

Hypothesis 3: Employees who view their workgroup as more cohesive will be more likely to demonstrate stronger workgroup commitment.

Integrating $\mathrm{H} 1-\mathrm{H} 3$, we propose that the Stay-Home orders will have a negative effect on workgroup commitment by reducing members' engagement in ritualistic workplace activities and consequently, by lowering perceptions that the workgroup is cohesive.

Hypothesis 4a: Workgroup commitment will decrease as COVID-19 Stay-Home orders continue to be in effect over time. 
Hypothesis 4b: The negative relationship between the Stay-Home orders and workgroup commitment will be sequentially mediated by the reduced engagement in ritualistic workplace activities and, consequently, lowered workgroup cohesion. ${ }^{5}$

\section{Differentiating Workgroup Commitment from Workgroup Identification}

The psychological relationship between employees and their workgroup has been conceptualized not just in terms of how committed employees are, but also how much they identify with their workgroups - that is, how much employees integrate their workgroup into their self-concept (Dutton et al., 1994; Mael \& Ashforth, 1992). Commitment and identification refer to a person's attachment to a group (e.g., Meyer et al., 2006; Riketta \& van Dick, 2005) and are closely related (e.g., $r=.78$ in Riketta's [2005] meta-analysis). Researchers have thus called for studies to distinguish the two constructs from one another (e.g., van Rossenberg et al., 2018).

Although both commitment and identification can be dynamic (Bednar et al., 2020; Klein et al., 2012), we suggest that changes in commitment to and identification with one's workgroup may show different trajectories over time in response to the dramatic workplace changes brought on by the Stay-Home orders. Commitment has been conceptualized as more behaviorally based than identification (Becker, 1960; Staw, 1981). Specifically, commitment answers the question, "How much do I want to invest in and provide benefits to the group?”, highlighting a behavioral orientation to contribute to the group's welfare. In contrast, identification addresses the degree to which a person integrates their workgroup into their self-concept, answering the question, "How much do I view the group as a part of who I am?”(e.g., Haslam, 2004; Hogg \& Terry, 2000). Accordingly, demonstrated pro-group behaviors tend to be more characteristic of commitment than of identification (e.g., Bergami \& Bagozzi, 2000; Marique \& Stinglhamber, 2011).

\footnotetext{
${ }^{5}$ A sequential (serial) multiple mediator model has two or more mediators, with one of the mediators being a cause of the other mediator (Hayes, 2015).
} 
Because groups that are more cohesive are also more cooperative (e.g., supporting one another via explicit behaviors; Mullen \& Copper, 1994; Chatman et al., 2019)—and groups perceived to be more cohesive are likewise inferred to engage in more cooperative behaviors (Gammage et al., 2001)—we further hypothesize that perceived group cohesion will influence commitment, which is driven by behavioral investments, more than it will influence identification. Identification is focused on whether the workgroup can contribute to group members' self-definition (e.g., Ashforth \& Schinoff, 2016) and thus, may be based on more stable properties of the group (such as the workgroup's external reputation) rather than more dynamic changes in members' perceived behavioral investments. Putting together the prediction that perceived cohesion will influence members' workgroup commitment more so than their workgroup identification with our prior hypotheses leads us to also expect that the Stay-Home orders will be associated with a larger decrease in workgroup commitment than in workgroup identification. See Figure 1 for our theoretical model.

Hypothesis 5a: Workgroup commitment will decrease more than workgroup identification as COVID-19 Stay-Home orders continue to be in effect over time. ${ }^{6}$

Hypothesis 5b: Reduced engagement in ritualistic workplace activities and lower perceived workgroup cohesion will influence the relation between Stay-Home orders and declining workgroup commitment more than it will influence the relation between StayHome orders and declining workgroup identification (moderated sequential mediation).

\section{Method}

We tested our hypotheses using a longitudinal design, collecting time-varying assessments of data from the same individuals to examine the stability of commitment during the onset of the COVID-19 Stay-Home orders. We also preregistered our measures, and several

\footnotetext{
${ }^{6}$ We are hypothesizing workgroup identification will change less than workgroup commitment, not that workgroup identification will exhibit no change. Since the self-concept can change over time, workgroup identification - as a component of the self-concept — can also change (e.g., Ashforth et al., 2008; Bednar et al., 2020; Schultz, 2016).
} 
research questions, on the Open Science Framework (OSF). We posted a preliminary preregistration after collecting wave 0 (https://tinyurl.com/covidprereg1) and an updated preregistration after collecting wave 2 (https://tinyurl.com/covidpreregv2). ${ }^{7}$

Participants. We administered four surveys to adult U.S. workers at the onset of the Stay-Home orders. At wave 0, which occurred shortly after the Stay-Home orders were announced, we recruited $N=1,000$ U.S. participants from Amazon Mechanical Turk who had been employed full-time prior to the COVID-19 pandemic. Excluding those who failed to follow instructions $(N=40$; see Appendix A), we invited all participants recruited in wave 0 to participate in waves 1-3; no one was excluded for nonresponse, and we retained partial responses in our analyses. To distinguish our results from the effects of job termination on commitment (e.g., Porter et al., 1974), we excluded participants who reported that they were not employed at the same organization for the duration of the study $(N=188)$, resulting in a final sample of 772 participants (see Table 1 for demographics). ${ }^{8}$ This exclusion, while not preregistered, provides a more conservative test of our hypothesis; we compare the full sample $(N=960)$ to the final sample $(N=772)$ in Appendix B. The response rate for the final sample $(N=772)$ was $80.96 \%$ in wave $1(625 / 772), 73.70 \%$ in wave $2(569 / 772)$, and $69.04 \%$ in wave $3(533 / 772)$.

Procedure. Across all four waves of data collection, we asked participants to "think about a workgroup with whom you're close. A workgroup is defined as an intact group of people who all know each other and work together." In wave 0 (collected on April 10), participants

\footnotetext{
${ }^{7}$ Notably, the survey was intended to capture a much broader set of research questions, which are reported in the preregistration. All survey items are also available on the OSF Repository for this project (https://osf.io/g6nua/?view_only=f79a6b5037ad49378ca986675a1bbd1b).

${ }^{8}$ In waves 1-3, we measured current employment status with the following item, "Which best describes your employment situation at the present time?" Participants $(N=772)$ who indicated they were "working for the same company as prior to the COVID-19 pandemic" in all the waves they participated were retained in the sample.
} 
retrospectively recalled their work experiences before the Stay-Home orders. ${ }^{9}$ In waves 1-3, participants reported their experiences with their workgroup "at the present time": wave 1 (April 18-22), wave 2 (May 19-24), and wave 3 (June 22-28). To ensure participants wrote about the same workgroup, in waves 2 and 3, we piped into the survey each participants' nickname for the workgroup. Participants completed the same measures in each survey wave (but survey items were phrased in the past tense for wave 0 only).

\section{Materials (Survey)}

Workgroup commitment. We measured workgroup commitment using four items: (1) “Are you strongly committed to your work group?"; (2) "Are you glad to contribute to your work group?"; (3) "Do you feel strongly affiliated with your work group?"; and (4) "Do you like to help your work group?" ( 1 = not at all, 5 = extremely; adapted from Klein et al., 2014, Roccas et al., $2008 ; \alpha=.92)$.

Workgroup identification. We measured workgroup identification with Bergami and Bagozzi’s (2000) Venn diagram method. Participants viewed seven pairs of circles that ranged from just touching to almost completely overlapping. One circle in each pair was labeled "You," and the second circle was labeled "Work Group" (see Figure 2 for the full scale). Participants selected the option that described their relationship with their workgroup, where "1" showed non-overlapping circles, and "7" showed almost entirely overlapping circles. Higher numbers indicate the circles are closer to overlapping, indicating higher workgroup identification.

Ritualistic workplace activities. To measure the degree to which individuals engaged in ritualistic workplace activities, we asked participants to:

"Please think about some specific instances of meaningful activities your work group did together in the past few weeks. List at least one and up to three activities below. For

\footnotetext{
${ }^{9}$ We asked participants to "think about a time that was just prior to the COVID-19 pandemic lockdown, such as in early January of this year." The wave 0 data collection thus established baseline levels of our measures.
} 
instance, maybe your work group played a game together, performed a warm-up chant together, or ate a meal together. The activities can be remote/virtual."

For each reported activity (up to three, in order to keep the survey brief), we asked participants to rate the degree to which it was ritualistic by answering the following question: "To what extent do you consider this group activity to be a tradition or ritual in your group? A tradition/ritual is an activity that symbolizes group values and tends to be done multiple times in the same specific way each time" ( 1 = not at all, 5 = very much; adapted from Garcia-Rada et al., 2019). Table 2 presents illustrative workgroup activities that participants reported to be high or low in ritualism. To compute our ritual index, for each survey wave we averaged participants' ratings of the workgroup activities' ritualism $(\alpha=.71)$. Because participants could list zero to three activities $(M=2.25$ activities, $S D=0.95)$, we substituted missing ritual ratings with 0 if a participant listed less than three activities. The results show an identical pattern when operationalizing ritual as simply the number of activities (i.e., 0, 1, 2, or 3 activities listed; see Appendix B).

Perceived workgroup cohesion. To measure workgroup cohesion, we asked participants to indicate how much their workgroup members: (1) "Share knowledge"; (2) "Have common goals"; (3) "Have strong interpersonal bonds"; (4) "Have shared rules (formal and informal) that you follow together"; (5) "Influence each other"; and (6) "Interact with each other" (1 = not at all, 5 = extremely; Denson et al., 2006; $\alpha=.87)$.

Control variables. To control for variables that past work has shown to correlate with commitment (e.g., Meyer et al., 2002), we report robustness tests controlling for demographic variables (gender, race/ethnicity, age, education, income), individual differences (personality, loneliness, perceived COVID-19 threat, individual COVID-19 infection), and group-level characteristics (in-person communication time, total communication time, intimacy of interactions, group member COVID-19 infection). All survey items are available in Appendix A. 


\section{Results}

We provide descriptive statistics and zero-order relationships for the study variables and selected demographic variables (across waves) in Table 1.

Analytic strategy. Our longitudinal design allows us to test within-person changes over time. To account for the nested data structure and to model the within-person effects for testing H1-H3, H4a, and H5a, we analyzed the data using multilevel modeling with observations nested within participant and a random slope to allow intra-individual predictors to vary between participants (random intercept and slope model; Aguinis et al., 2013). We centered all intraindividual predictors around the mean for each individual and controlled for the (aggregated) person-means of the intra-individual predictors to isolate within-person (rather than betweenperson) effects (“within-between formulation"; Bell \& Jones, 2015). This within-between approach allows us to remove average variation between persons and focus on within-person variation, which corrects for unobserved heterogeneity bias.

To test $\mathrm{H} 4 \mathrm{~b}$ and $\mathrm{H} 5 \mathrm{~b}$, we employed a path modeling approach which, consistent with our theory, allows us to examine multiple dependent variables and allows for variables to be both independent and dependent in a single analysis (Kline, 2015). ${ }^{10}$ To account for the nested data structure, we again employed a within-between formulation and used cluster-robust standard errors. In all analyses, we operationalize the duration of COVID-19 Stay-Home orders as survey waves - $0,1,2,3$ - which represent the length of time since the Stay-Home orders were enacted.

Main Results. Consistent with our theoretical model, we found a negative relationship between the duration of Stay-Home orders and ritualistic workplace activities such that, as the duration of Stay-Home orders increased, ritualistic workplace activities declined $(\mathrm{H} 1), \beta=-0.25$,

\footnotetext{
${ }^{10}$ For instance, in H4b, ritualistic activities serve as both a dependent variable (predicted by Stay-Home orders) and an independent variable (predicts perceived cohesion and workgroup commitment).
} 
$S E(\beta)=0.015, t(1150.35)=-16.40, p<.001$. We also found, as predicted, a positive relationship between ritualistic workplace activities and perceived cohesion $(\mathrm{H} 2), \beta=0.21, S E(\beta)=0.015$, $t(478.07)=13.71, p<.001$, and a positive relationship between perceived cohesion and workgroup commitment (H3), $\beta=0.27, \operatorname{SE}(\beta)=0.013, t(376.60)=20.86, p<.001$. And, as we expected (H4a), the duration of Stay-Home orders was associated with a decrease in members' workgroup commitment, $\beta=-0.09, \operatorname{SE}(\beta)=0.012, t(617.59)=-7.62, p<.001$.

Providing support for $\mathrm{H} 4 \mathrm{~b}$, the $95 \% \mathrm{CI}$ for the index of sequential mediation did not include zero, indicating a significant sequential mediation effect of Stay-Home orders on workgroup commitment through ritualistic workplace activities and perceived cohesion (Sequential Mediation Index $=-0.025, S E=0.003,95 \%$ CI $[-0.032,-0.019]$ ). See Table 3.

To test $\mathrm{H} 5 \mathrm{a}$, we regressed standardized ratings of commitment and identification on duration of Stay-Home orders, an indicator for commitment ("1") or identification ("-1"), and their product term. There was an effect of Stay-Home orders, $\beta=-0.07, \operatorname{SE}(\beta)=0.010, t(602.63)$ $=-7.21, p<.001$, but no effect of commitment/identification, $\beta=0.01, S E(\beta)=0.017, t(868.90)$ $=0.75, p=.455$, which indicates ratings of commitment and identification did not differ at wave 0 . As predicted, an interaction emerged, indicating workgroup commitment and identification showed distinct patterns in relation to the duration of Stay-Home orders, $\beta=-0.02, S E(\beta)=$ $0.007, t(2856.60)=-2.38, p=.017$. Supporting H5a, the relationship between duration of StayHome orders and identification was weaker, $\beta=-0.06, S E(\beta)=0.012, t(775.73)=-4.56, p<$ .001 , than was the relationship between duration of Stay-Home orders and commitment, $\beta=-$ $0.09, S E(\beta)=0.013, t(749.95)=-7.19, p<.001$. See Figure 3.

Providing support for our predicted moderated sequential mediation pathway in $\mathrm{H} 5 \mathrm{~b}$, the 95\% CI for the index of moderated sequential mediation did not include zero, indicating 
commitment versus identification moderated the sequential mediation effect of ritualistic workplace activities and perceived cohesion $($ Moderated Sequential Mediation Index $=-0.010$, $S E=0.004,95 \%$ CI $[-0.016,-0.003])$. As we predicted, the sequential mediation effect via ritualistic activities and perceived cohesion was stronger on commitment (Indirect Effect $=$ $0.049, S E=0.006,95 \% \mathrm{CI}[-0.062,-0.037])$ than on identification (Indirect Effect $=-0.040, S E=$ $0.005,95 \%$ CI $[-0.050,-0.030])$. See Figure 4 and Table 4.

Robustness analyses. As shown in Table 5, the statistical significance and direction of H1-H5b remain unchanged when controlling for these variables, ruling out an array of alternative explanations for our findings. None of these alternative constructs, such as the amount of time workgroups spend communicating, account for our hypothesized relationships. See Appendix B.

\section{Supplemental Data: Preregistered Replication}

We conducted a preregistered survey to replicate our results, recruiting 203 U.S. adults who were working full-time from Prolific Academic (59\% male; $M_{\text {age }}=35.49, S D_{\text {age }}=9.62$; https://aspredicted.org/blind.php? $\mathrm{x}=\mathrm{ji} 3 \mathrm{hf3}$ ). We briefly summarize our findings here and provide complete details in Appendix C. We again surveyed participants about workgroup rituals following the onset of Stay-Home orders in the U.S. (March to June 2020). Replicating the results of our main study, engaging in ritualistic activities was associated with perceived workgroup cohesion (H2), $\beta=0.32, p<.001$, and workgroup commitment, $\beta=0.41, p<.001$. A significant interaction of cohesion $\times$ commitment/identification interaction emerged, $\beta=0.17, p$ $=.002$, such that perceived cohesion was more associated with commitment (H3), $\beta=0.62, p<$ .001 , than with identification, $\beta=0.45, p<.001$, again supporting (H5b).

Beyond providing a preregistered replication, the supplemental data offer two additional contributions. First, we used a different measure of workgroup identification (Mael \& Ashforth, 
1992), increasing construct validity. Second, we asked participants to code their workplace rituals to further validate our conception and operationalization of ritualistic workplace activities. Examining the mode value of participants' codes indicates that ritualistic workplace activities after the Stay-Home orders most commonly were: unconnected to consuming food or drink, performed online, social in nature, classified as work meetings (vs. social activities), attended by the entire (vs. part of the) workgroup, created by the manager of the group, and important to the workgroup's values. We summarize participants' responses in Table 6.

\section{General Discussion}

The COVID-19 pandemic has been unprecedented in terms of its suddenness and impact on modern employees' experience at work. We used this crisis to advance understanding about employees' commitment to and identification with their workgroup. Analyzing survey responses from 772 U.S. workers at the onset of the COVID-19 Stay-Home orders using a within-person, longitudinal data approach, we demonstrate that: (a) the duration of the Stay-Home orders was negatively related to workgroups engaging in ritualistic workplace activities, which was subsequently associated with lower perceived workgroup cohesion, and ultimately, less workgroup commitment; and (b) workgroup commitment declined more than workgroup identification over the period. Moreover, our analytic strategy, which eliminates between-person variation by focusing on within-person variation, combined with robustness tests that control for a host of employee and workgroup characteristics, provides evidence that our theorized relationships are not driven by likely alternative constructs (e.g., workgroup communication time).

\section{Theoretical and Practical Implications}


Our findings offer several theoretical and practical implications. First, our research serves as a timely attempt to capitalize on the COVID-19 pandemic to examine how a sudden, vast, and naturally occurring exogenous shock (Waldinger, 2012) affects workgroup commitment over time. As such, our study reveals insights about commitment that might not have emerged in more contrived laboratory settings or using static research designs, or even dynamic field designs over a stable period of time. Prior research has assumed that commitment is stable once it is developed (e.g., Meyer \& Allen, 1997). By showing that workgroup commitment decreased as the duration of Stay-Home orders increased, and by examining the mechanisms underlying the decline in commitment (i.e., engagement in ritualistic activities and perceived cohesion), our work contributes to understanding the time trajectory of commitment following a change in work conditions. In so doing, we identify an essential quality of commitment: it declines as a function of members' reduced ability to engage in ritualistic activities which emphasize the group's cohesion. Our research thus adds to a growing but small literature on how commitment changes over time (e.g., Becker et al., 2012; Kam et al., 2016; Solinger et al., 2015). Practically, our results indicate that employees facing negative workplace events that interfere with their ability to interact with their workgroup, or even increasingly, working more frequently at a distance from their workgroups (e.g., Ashford, Caza, \& Reid, 2018), may experience declining workgroup commitment - but that maintaining ritualistic workgroup activities could be a way to buffer against such events and trends.

Second, our results show that, despite their conceptual overlap, commitment appears to be less stable than identification during the COVID-19 Stay-Home orders. Commitment declined more as the duration of Stay-Home orders increased because commitment (vs. identification) is more influenced by perceptions that the workgroup is behaviorally cohesive, which is influenced 
by engagement in ritualistic activities. Our results answer recent calls to differentiate the constructs of commitment and identification (e.g., van Rossenberg et al., 2018) and complement past work which has, for example, shown that that identification plays a role in the development of commitment, but not vice versa (e.g., Ellemers et al., 1997; Stinglhamber et al., 2015).

Lastly, we offer insights about the role of ritualistic workplace activities in perceived cohesion and member commitment, a phenomenon that has long been viewed as important in cultivating a strong organizational culture (Trice \& Beyer, 1984; Islam \& Zyphur, 2009) but rarely studied as influencing workgroup commitment. Our results show how engaging in rituals affects employees' perceptions of workgroup cohesion, which subsequently affects workgroup commitment. Moreover, we provide insight into how ritualistic activities take shape within organizations. While rituals have traditionally been studied from sociocultural perspectives (e.g., Durkheim, 1915; Rappaport, 1999), we show that workgroups can ritualize "mundane" activities (e.g., work meetings) when they make the activities more physically rigid (e.g., occurring at the same time/place) and imbue them with meaning by connecting them to workgroup values.

\section{Limitations and Future Directions}

Our research is subject to several limitations that present opportunities for future research. First, despite our longitudinal approach, we cannot rule out threats to causal identification from other forms of endogeneity (e.g., unobserved attributes of individuals that change over time), suggesting that field experiments that manipulate workgroup's ritualistic behaviors and measure subsequent group cohesion and commitment could be helpful. Second, we examined the immediate aftermath (three months post-onset) of the Stay-Home orders based on a specific crisis. Future research could explore the generalizability of our results to nonpandemic and more enduring challenges, examining how and when workgroups engage in 
rituals. Given the value of remote work in increasing parity for diverse employees (Leslie et al., 2012), there may be ways to replicate the psychological advantages of rituals in more flexible settings. Third, future research might more directly examine the behaviors associated with workgroup rituals, rather than rely on self-reported evidence, to learn more about the differences in the types of practices that become highly ritualized. Fourth, our research focused on workgroups as a foci of commitment, but changes in commitment to other foci may exhibit a different pace in response to change (Becker, 2009). Future research could examine, for example, whether commitment to professional groups is less subject to decline as a result of engaging in ritualistic behaviors because there is a lower base rate of such behaviors to begin with. Finally, we focused on the mechanisms driving changes in commitment and how changes in identification with the workgroup was less sensitive to these mechanisms. Future research should continue to examine the mechanisms that are distinctly related to changes in identification (Bednar et al., 2020).

\section{Conclusion}

Workgroup commitment is an important bond that influences a variety of workplace behaviors. Our study suggests that the sudden and vast restrictions prompted by the COVID-19 pandemic has meaningfully influenced how employees engage with one another, and subsequently reduced employees' workgroup commitment. By offering insight into the reduction in workgroup commitment during a pandemic, we help to better illuminate how commitment operates and build a more robust theoretical understanding of commitment as well as how employees can withstand events that challenge their ability to connect with their workgroup. 


\section{References}

Aguinis, H., Gottfredson, R. K., \& Culpepper, S. A. (2013). Best-practice recommendations for estimating cross-level interaction effects using multilevel modeling. Journal of Management, 39(6), 1490-1528.

Ashford, S. J., Caza, B. B., \& Reid, E. M. (2018). From surviving to thriving in the gig economy: A research agenda for individuals in the new world of work. Research in Organizational Behavior, 38, 23-41.

Ashforth, B. E., \& Mael, F. (1989). Social identity theory and the organization. The Academy of Management Review, 14(1), 20-39.

Ashforth, B. E., \& Schinoff, B. S. (2016). Identity under construction: How individuals come to define themselves in organizations. Annual Review of Organizational Psychology and Organizational Behavior, 3, 111-137.

Bartel, C. A., Wrzesniewski, A., \& Wiesenfeld, B. M. (2012). Knowing where you stand: Physical isolation, perceived respect, and organizational identification among virtual employees. Organization Science, 23(3), 743-757.

Becker, H. S. (1960). Notes on the concept of commitment. American Journal of Sociology, $66(1), 32-40$.

Becker, T. E. (2009). Interpersonal commitments. In H. J. Klein, T. E. Becker, \& J. P. Meyer (Eds.), SIOP organizational frontiers series. Commitment in organizations: Accumulated wisdom and new directions (p. 137-178). Routledge/Taylor \& Francis Group.

Becker, T. E. (1992). Foci and bases of commitment: Are they distinctions worth making? Academy of Management Journal, 35(1), 232-244. 
Becker, T. E., Ullrich, J., \& van Dick, R. (2013). Within-person variation in affective commitment to teams: Where it comes from and why it matters. Human Resource Management Review, 23(2), 131-147.

Bednar, J. S., Galvin, B. M., Ashforth, B. E., \& Hafermalz, E. (2020). Putting identification in motion: A dynamic view of organizational identification. Organization Science, 31(1), 200-222.

Bell, A., \& Jones, K. (2015). Explaining Fixed Effects: Random Effects Modeling of TimeSeries Cross-Sectional and Panel Data. Political Science Research and Methods, 3(1), $133-153$.

Bergdahl M. 2004. What I Learned from Sam Walton: How to Compete and Thrive in a WalMart World. Hoboken: Wiley

Bergami, M., \& Bagozzi, R. P. (2000). Self-categorization, affective commitment and group selfesteem as distinct aspects of social identity in the organization. British Journal of Social Psychology, 39(4), 555-577.

Bergman, M. E., \& Jean, V. A. (2016). Individual differences as causes of the development of commitment. In J.P. Meyer (Ed.), Handbook of Employee Commitment. Cheltenham, UK: Edward Elgar Publishing.

Boyer, P., Liénard, P. (2020). Ingredients of 'Rituals' and Their Cognitive Underpinnings. Philosophical Transactions of the Royal Society of London. Series B, Biological Sciences, 375(1805), 1-6.

Caldwell, D. F., Chatman, J. A., \& O'Reilly, C. A. (1990). Building organizational commitment: A multifirm study. Journal of Occupational Psychology, 63(3), 245-261. 
Campbell, D. T. (1958). Common fate, similarity, and other indices of the status of aggregates of persons as social entities. Behavioral Science, 3(1), 14-25.

Chatman, J., Greer, L., Sherman, E., \& Doerr, B. (2019). Blurred lines: How collectivism mutes the disruptive and elaborating effects of demographic heterogeneity in Himalayan expeditions. Organization Science, 30 (2): 235-259.

Chatman, J., \& O'Reilly, C. (2016). Paradigm lost: Reinvigorating the study of organizational culture. Research in Organizational Behavior, 36, 199-224.

Chong, S., Huang, Y., \& Chang, C.-H. (D.). (2020). Supporting interdependent telework employees: A moderated-mediation model linking daily COVID-19 task setbacks to next-day work withdrawal. Journal of Applied Psychology, 105(12), 14081422.

Conway III, L. G., Woodard, S. R., \& Zubrod, A. (2020). Social psychological measurements of COVID-19: Coronavirus perceived threat, government response, impacts, and experiences questionnaires. Working paper.

Denson, T. F., Lickel, B., Curtis, M., Stenstrom, D. M., \& Ames, D. R. (2006). The roles of entitativity and essentiality in judgments of collective responsibility. Group Processes \& Intergroup Relations, 9(1), 43-61.

Durkheim, E. (1915). The Elementary Forms of the Religious Life: A Study in Religious Sociology. Macmillan.

Dutton, J. E., Dukerich, J. M., \& Harquail, C. V. (1994). Organizational images and member identification. Administrative Science Quarterly, 39(2), 239-263. 
Ellemers, N., Spears, R., \& Doosje, B. (1997). Sticking together or falling apart: In-group identification as a psychological determinant of group commitment versus individual mobility. Journal of Personality and Social Psychology, 72(3), 617-626.

Garcia-Rada, X., Sezer, O., \& Norton, M. I. (2019). Rituals and nuptials: The emotional and relational consequences of relationship rituals. Journal of the Association for Consumer Research, 4(2), 185-197.

Gosling, S. D., Rentfrow, P. J., \& Swann, W. B., Jr. (2003). A very brief measure of the Big-Five personality domains. Journal of Research in Personality, 37(6), 504-528.

Gammage, K. L., Carron, A. V., \& Estabrooks, P. A. (2001). Team cohesion and individual productivity: The influence of the norm for productivity and the identifiability of individual effort. Small Group Research, 32(1), 3-18.

Haslam, S. A. (2004). Psychology in organizations: The social identity approach. SAGE Publications Inc.

Hamilton, D. L., Sherman, S.J., \& Castelli, L. (2002). A group by any other name - The role of entitativity in group perception. European Review of Social Psychology, 12, 139-166.

Hayes, A. F. (2015). An index and test of linear moderated mediation. Multivariate Behavioral Research, 50(1), 1-22.

Hobson, N. M., Schroeder, J., Risen, J. L., Xygalatas, D., \& Inzlicht, M. (2018). The Psychology of Rituals: An Integrative Review and Process-Based Framework. Personality and Social Psychology Review, 22(3), 260-284.

Hogg, M. A., \& Terry, D. J. (2000). Social identity and self-categorization processes in organizational contexts. The Academy of Management Review, 25(1), 121-140. 
Hu, J., He, W., \& Zhou, K. (2020). The mind, the heart, and the leader in times of crisis:

How and when COVID-19-triggered mortality salience relates to state anxiety, job engagement, and prosocial behavior. Journal of Applied Psychology, 105(11), 12181233.

Islam, G., \& Zyphur, M. J. (2009). Rituals in organizations. Group \& Organization Management, 34(1), 114-139.

Kam, C., Morin, A.J.S., Meyer, J.P., \& Topolnytsky, L. (2016). Are commitment profiles stable and predictable? A latent transition analysis. Journal of Management, 42(6), 14621490.

Klein, H. J., Cooper, J. T., Molloy, J. C., \& Swanson, J. A. (2014). The assessment of commitment: advantages of a unidimensional, target-free approach. Journal of Applied Psychology, 99(2), 222.

Klein, H. J., Molloy, J. C., \& Brinsfield, C. T. (2012). Reconceptualizing workplace commitment to redress a stretched construct: Revisiting assumptions and removing confounds. The Academy of Management Review, 37(1), 130-151.

Kline, R. B. (2015). Principles and practice of structural equation modeling. (3rd ed.). Guilford Press.

Kniffin, K. M., Narayanan, J., Anseel, F., Antonakis, J., Ashford, S. P., Bakker, A. B., .. . Vugt, M. v. (2021). COVID-19 and the workplace: Implications, issues, and insights for future research and action. American Psychologist, 76(1), 63-77.

Lakens, D. (2010). Movement synchrony and perceived entitativity. Journal of Experimental Social Psychology, 46(5), 701-708. 
Leslie, L. M., Manchester, C. F., Park, T. Y., \& Mehng, S. A. (2012). Flexible work practices: a source of career premiums or penalties? Academy of Management Journal, 55(6), 14071428.

Mael, F., \& Ashforth, B. E. (1992). Alumni and their alma mater: A partial test of the reformulated model of organizational identification. Journal of Organizational Behavior, 13(2), 103-123.

Marique, G., \& Stinglhamber, F. (2011). Identification to proximal targets and affective organizational commitment: The mediating role of organizational identification. Journal of Personnel Psychology, 10(3), 107-117.

Meyer, J. P., \& Allen, N. J. (1997). Advanced topics in organization behavior series. Commitment in the workplace: Theory, research, and application. SAGE Publications, Inc.

Meyer, J. P., Becker, T. E., \& Van Dick, R. (2006). Social identities and commitments at work: Toward an integrative model. Journal of Organizational Behavior, 27(5), 665-683.

Meyer, J. P., Stanley, L. J., Herscovitch, L., \& Topolnytsky, L. (2002). Affective, continuance, and normative commitment to the organization: A meta-analysis of antecedents, correlates, and consequences. Journal of Vocational Behavior, 61(1), 20-52.

Mullen, B., \& Copper, C. (1994). The relation between group cohesiveness and performance: An integration. Psychological Bulletin, 115(2), 210-227.

Norton, M. I., \& Gino, F. (2014). Rituals alleviate grieving for loved ones, lovers, and lotteries. Journal of Experimental Psychology: General, 143(1), 266. 
O'Reilly, C. A., \& Chatman, J. (1986). Organizational commitment and psychological attachment: The effects of compliance, identification, and internalization on prosocial behavior. Journal of Applied Psychology, 71(3), 492.

Podsakoff, P. M., MacKenzie, S. B., Lee, J.-Y., \& Podsakoff, N. P. (2003). Common method biases in behavioral research: A critical review of the literature and recommended remedies. Journal of Applied Psychology, 88(5), 879-903.

Porter, L., Steers, R., Mowday, R., \& Boulian, P. (1974). Organizational commitment, job satisfaction, and turnover among psychiatric technicians. Journal of Applied Psychology, 59, 603-609.

Rappaport, R. A. (1999). Ritual and religion in the making of humanity. Cambridge University Press.

Riketta, M. (2005). Organizational identification: A meta-analysis. Journal of Vocational Behavior, 66(2), 358-384.

Riketta, M., \& van Dick, R. (2005). Foci of attachment in organizations: A meta-analytic comparison of the strength and correlates of workgroup versus organizational identification and commitment. Journal of Vocational Behavior, 67(3), 490-510.

Roccas, S., Sagiv, L., Schwartz, S., Halevy, N., \& Eidelson, R. (2008). Toward a unifying model of identification with groups: Integrating theoretical perspectives. Personality and Social Psychology Review, 12(3), 280-306.

Schroeder, J., Kardas, M., \& Epley, N. (2017). The humanizing voice: Speech reveals, and text conceals, a more thoughtful mind in the midst of disagreement. Psychological Science, 28(12), 1745-1762. 
Schultz, M. (2016). Organizational Identity Change \& Temporality. In M. G. Pratt, M. Schultz, B. E. Ashforth, \& D. Ravasi (Eds.), The Oxford Handbook of Organizational Identity (pp. 93-105). Oxford University Press.

Sezer, O., Norton, M. I., Gino, F., \& Vohs, K. D. (2016). Family rituals improve the holidays. Journal of the Association for Consumer Research, 1(4), 509-526.

Smith, F. J. (1977). Work attitudes as predictors of attendance on a specific day. Journal of Applied Psychology, 62(1), 16.

Solinger, O. N., Hofmans, J. \& Olffen, W. (2015). The dynamic microstructure of organizational commitment. Journal of Occupational and Organizational Psychology, 88(4), 773-796.

Solinger, O. N., van Olffen, W., \& Roe, R. A. (2008). Beyond the three-component model of organizational commitment. Journal of Applied Psychology, 93(1), 70-83.

Staw, B. M. (1981). The escalation of commitment to a course of action. The Academy of Management Review, 6(4), 577-586.

Stein, D. H., Hobson, N. M., \& Schroeder, J. (2021). A sacred commitment: How rituals promote group survival. Current Opinion in Psychology, 40, 114-120.

Stein, D. H., Schroeder, J., Hobson, N. M., Gino, F., \& Norton, M. I. (2021). When alterations are violations: Moral outrage and punishment in response to (even minor) alterations to rituals. Journal of Personality and Social Psychology.

Stinglhamber, F., Marique, G., Caesens, G., Desmette, D., Hansez, I., Hanin, D., \& Bertrand, F. (2015). Employees' organizational identification and affective organizational commitment: An integrative approach. PLoS One, 10(4), 1-23. 
Swann, W. B., Jr, Gómez, A., Seyle, D. C., Morales, J. F., \& Huici, C. (2009). Identity fusion: the interplay of personal and social identities in extreme group behavior. Journal of Personality and Social Psychology, 96(5), 995-1011.

Trice, H., \& Beyer, J. (1984). Studying Organizational Cultures through Rites and Ceremonials. The Academy of Management Review, 9(4), 653-669.

Trougakos, J. P., Chawla, N., \& McCarthy, J. M. (2020). Working in a pandemic: Exploring the impact of COVID-19 health anxiety on work, family, and health outcomes. Journal of Applied Psychology, 105(11), 1234-1245.

van Bavel, J. J., Baicker, K., Boggio, P. S., Capraro, V., Cichocka, A., Cikara, M., Crockett, M. J., Crum, A. J., Douglas, K. M., Druckman, J. N., Drury, J., Dube, O., Ellemers, N., Finkel, E. J., Fowler, J. H., Gelfand, M., Han, S., Haslam, S. A., Jetten, J., ... Willer, R. (2020). Using social and behavioural science to support COVID-19 pandemic response. Nature Human Behavior, 4(5), 460-471.

van Dick, R. (2016). Organizational identification. In J.P. Meyer (Ed.), Handbook of Employee Commitment. Cheltenham, UK: Edward Elgar Publishing.

van Rossenberg, Y. G. T., Klein, H. J., Asplund, K., Bentein, K., Breitsohl, H., Cohen, A., Cross, D., de Aguiar Rodrigues, A. C., Duflot, V., Kilroy, S., Ali, N., Rapti, A., Ruhle, S., Solinger, O., Swart, J., \& Yalabik, Z. Y. (2018). The future of workplace commitment: key questions and directions. European Journal of Work and Organizational Psychology, 27(2), 153-167.

Waldinger, F. (2012). Peer effects in science: Evidence from the dismissal of scientists in Nazi Germany. The Review of Economic Studies, 79(2), 838-861. 
Watson-Jones, R. E., \& Legare, C. H. (2016). The social functions of group rituals. Current Directions in Psychological Science, 25(1), 42-46.

Yzerbyt, V., Judd, C. M., \& Corneille, O. (2004). The psychology of group perception: Perceived variability, entitativity, and essentialism. Psychology Press.

Zaccaro, S. J., \& Dobbins, G. H. (1989). Contrasting group and organizational commitment: Evidence for differences among multilevel attachments. Journal of Organizational Behavior, 267-273. 


\section{Tables}

\section{Table 1}

Means, standard deviations, and zero-order correlations with confidence intervals

\begin{tabular}{|c|c|c|c|c|c|c|c|c|c|c|}
\hline Variable & $M$ & $S D$ & 1 & 2 & 3 & 4 & 5 & 6 & 7 & 8 \\
\hline 1. Commitment & 3.88 & 0.96 & & & & & & & & \\
\hline 2. Identification & 3.82 & 1.52 & $\begin{array}{c}.55^{* *} \\
{[.52, .58]}\end{array}$ & & & & & & & \\
\hline 3. Ritualistic activities & 2.53 & 1.40 & $\begin{array}{l}.26^{* *} \\
{[.22, .29]}\end{array}$ & $\begin{array}{l}.31 * * \\
{[.28, .35]}\end{array}$ & & & & & & \\
\hline $\begin{array}{l}\text { 4. Perceived } \\
\text { workgroup cohesion }\end{array}$ & 3.71 & 0.78 & $\begin{array}{l}.73 * * \\
{[.71, .74]}\end{array}$ & $\begin{array}{l}.57 * * \\
{[.54, .60]}\end{array}$ & $\begin{array}{l}.35 * * \\
{[.32, .38]}\end{array}$ & & & & & \\
\hline 5. Female (d) & 0.42 & 0.49 & $\begin{array}{l}.05^{*} \\
{[.01, .09]}\end{array}$ & $\begin{array}{c}-.11 * * \\
{[-.15,-.07]}\end{array}$ & $\begin{array}{l}-.01 \\
{[-.05, .03]}\end{array}$ & $\begin{array}{c}.02 \\
{[-.02, .06]}\end{array}$ & & & & \\
\hline 6. Non-White (d) & 0.24 & 0.43 & $\begin{array}{l}-.03 \\
{[-.07, .01]}\end{array}$ & $\begin{array}{c}.05 * * \\
{[.01, .09]}\end{array}$ & $\begin{array}{c}.02 \\
{[-.02, .06]}\end{array}$ & $\begin{array}{c}-.01 \\
{[-.05, .03]}\end{array}$ & $\begin{array}{c}-.10^{* *} \\
{[-.13,-.06]}\end{array}$ & & & \\
\hline 7. Age & 38.03 & 10.65 & $\begin{array}{l}.16^{* *} \\
{[.12, .20]}\end{array}$ & {$[-.07, .01]$} & $\begin{array}{l}-.03 \\
{[-.06, .01]}\end{array}$ & $\begin{array}{l}.09 * * \\
{[.05, .13]}\end{array}$ & $\begin{array}{c}.12 * * \\
{[.09, .16]}\end{array}$ & $\begin{array}{c}-.16^{* *} \\
{[-.20,-.12]}\end{array}$ & & \\
\hline 8. College (d) & 0.19 & 0.39 & $\begin{array}{l}.04^{*} \\
{[.00, .08]}\end{array}$ & $\begin{array}{l}.04 * \\
{[.00, .08]}\end{array}$ & $\begin{array}{l}.05^{*} \\
{[.01, .09]}\end{array}$ & $\begin{array}{c}.02 \\
{[-.01, .06]}\end{array}$ & {$[-.03$} & $\begin{array}{l}.06^{* *} \\
{[.02, .10]}\end{array}$ & $\begin{array}{l}.12 * * \\
{[.08, .16]}\end{array}$ & \\
\hline 9. Income & 5.08 & 1.51 & $\begin{array}{l}.16^{* *} \\
{[.12, .20]}\end{array}$ & $\begin{array}{c}.08 * * \\
{[.04, .12]}\end{array}$ & $\begin{array}{l}.04 * \\
{[.00, .08]}\end{array}$ & $\begin{array}{l}.12 * * \\
{[.08, .16]}\end{array}$ & $\begin{array}{c}-.07 * * \\
{[-.10,-.03]}\end{array}$ & $\begin{array}{l}-.01 \\
{[-.05, .03]}\end{array}$ & $\begin{array}{l}.10^{* *} \\
{[.06, .14]}\end{array}$ & $\begin{array}{c}.25^{* *} \\
{[.21, .28]}\end{array}$ \\
\hline
\end{tabular}

Notes: $M$ and $S D$ are used to represent mean and standard deviation, respectively. Values in square brackets indicate the $95 \%$ confidence interval for each correlation. * indicates $p$ $<.05$. ** indicates $p<.01$. (d) $=$ dummy coded variable. 


\section{Table 3}

Standardized Coefficients ( $\beta$ ), Standard Errors (SE), Z values, and p values for Sequential Mediation Effect on Workgroup Commitment (H4b)

\begin{tabular}{|c|c|c|c|c|}
\hline & $\beta$ & $S E$ & $Z$ value & $p$ value \\
\hline & \multicolumn{4}{|c|}{ M1: Ritualistic Workplace Activities } \\
\hline \multirow{3}{*}{$\begin{array}{l}\text { Stay-Home } \\
\text { Orders [X] }\end{array}$} & -0.30 & 0.019 & 16.11 & $<.001$ \\
\hline & & & & \\
\hline & \multicolumn{4}{|c|}{ M2: Perceived Workgroup Cohesion } \\
\hline Stay-Home & -0.10 & 0.020 & 4.91 & $<.001$ \\
\hline \multirow{4}{*}{$\begin{array}{l}\text { Orders [X] } \\
\text { Ritualistic } \\
\text { Activities [M1] }\end{array}$} & & & & \\
\hline & 0.32 & 0.028 & 11.07 & $<.001$ \\
\hline & & & & \\
\hline & \multicolumn{4}{|c|}{ Y: Workgroup Commitment } \\
\hline Stay-Home & -0.02 & 0.011 & -1.83 & .067 \\
\hline \multicolumn{5}{|l|}{ Orders $[\mathrm{X}]$} \\
\hline Ritualistic & 0.02 & 0.012 & 1.26 & .206 \\
\hline \multicolumn{5}{|l|}{ Activities [M1] } \\
\hline Perceived & 0.27 & 0.016 & 16.87 & $<.001$ \\
\hline Cohesion [M2] & & & & \\
\hline
\end{tabular}

Notes: Employing the within-between formulation (Bell \& Jones, 2015), the coefficients represent the expected change in the dependent variable corresponding to a $1 \mathrm{SD}$ change in the predictor relative to the participant's average (within-person effect), controlling for between-person differences in average levels of the predictor. For instance, the 0.32 coefficient linking ritualistic activities and perceived cohesion indicates a typical participant experienced a 0.32 SD unit increase in perceived cohesion when they experienced a 1 SD unit increase in their level of ritualistic activities (compared to the level of ritualistic activities they typically did in the survey time period). 


\section{Table 4}

Standardized Coefficients ( $\beta$ ), Standard Errors (SE), Z values, and p values for Sequential Mediation Effect of Workgroup Commitment versus Identification (H5b)

\begin{tabular}{|c|c|c|c|c|}
\hline & $\beta$ & $S E$ & $Z$ value & $p$ value \\
\hline & \multicolumn{4}{|c|}{ M1: Ritualistic Workplace Activities } \\
\hline \multirow{3}{*}{$\begin{array}{l}\text { Stay-Home } \\
\text { Orders [X] }\end{array}$} & -0.30 & 0.019 & 16.13 & $<.001$ \\
\hline & & & & \\
\hline & \multicolumn{4}{|c|}{ M2: Perceived Group Cohesion } \\
\hline \multirow{5}{*}{$\begin{array}{l}\text { Stay-Home } \\
\text { Orders [X] } \\
\text { Ritualistic } \\
\text { Activities [M1] }\end{array}$} & -0.10 & 0.020 & -4.91 & $<.001$ \\
\hline & & & & \\
\hline & 0.32 & 0.028 & 11.06 & $<.001$ \\
\hline & & & & \\
\hline & \multicolumn{4}{|c|}{ Y: Ratings of Workgroup Commitment or Identification } \\
\hline Stay-Home & -0.02 & 0.015 & -1.57 & .116 \\
\hline \multicolumn{5}{|l|}{ Orders $[\mathrm{X}]$} \\
\hline Ritualistic & 0.05 & 0.019 & 2.69 & .007 \\
\hline \multicolumn{5}{|l|}{ Activities [M1] } \\
\hline Perceived & 0.41 & 0.026 & 16.19 & $<.001$ \\
\hline \multicolumn{5}{|l|}{ Cohesion [M2] } \\
\hline Commitment & 0.00 & 0.000 & 0.90 & .370 \\
\hline (vs. & & & & \\
\hline \multicolumn{5}{|l|}{ Identification) } \\
\hline \multicolumn{5}{|l|}{$[\mathrm{W}]$} \\
\hline Perceived & 0.10 & 0.034 & 2.94 & .003 \\
\hline \multicolumn{5}{|l|}{ Cohesion $x$} \\
\hline \multicolumn{5}{|l|}{ Commitment } \\
\hline \multicolumn{5}{|l|}{$\begin{array}{l}\text { (vs. } \\
\text { Identification) }\end{array}$} \\
\hline \multicolumn{5}{|l|}{ Identification) } \\
\hline$[\mathrm{M} 2 \times \mathrm{W}]$ & & & & \\
\hline
\end{tabular}

Notes: Commitment (vs. Identification) is dummy coded (" 1 " = commitment, " 0 " = identification). As in Table 3, the coefficients represent the expected change in the dependent variable corresponding to a $1 \mathrm{SD}$ change in the predictor relative to the participant's average (within-person effect), controlling for between-person differences in average levels of the predictor (Bell \& Jones, 2015). 
Table 5

Robustness Results Controlling for Employee and Workgroup Characteristics

\begin{tabular}{|c|c|c|}
\hline Hypothesis & Relationship & $\begin{array}{l}\text { Standardized Coefficient and } \\
95 \% \text { CI }\end{array}$ \\
\hline 1 & $\begin{array}{l}\text { Stay-Home Orders }[\mathrm{X}] \rightarrow \\
\text { Ritualistic Activities [M1] }\end{array}$ & $-0.30[-0.33,-0.27]$ \\
\hline 2 & $\begin{array}{l}\text { Ritualistic Activities [M1] } \rightarrow \\
\text { Perceived Cohesion [M2] }\end{array}$ & $0.16[0.14,0.19]$ \\
\hline 3 & $\begin{array}{l}\text { Perceived Cohesion [M2] } \rightarrow \\
\text { Commitment [Y] }\end{array}$ & $0.26[0.24,0.29]$ \\
\hline $4 a$ & $\begin{array}{l}\text { Stay-Home Orders }[\mathrm{X}] \rightarrow \\
\text { Commitment }[\mathrm{Y}]\end{array}$ & $-0.11[-0.14,-0.09]$ \\
\hline $4 b$ & $\begin{array}{l}\text { Serial Mediation Indirect Effect } \\
\text { on Commitment } \\
{[\mathrm{X} \rightarrow \mathrm{M} 1 \rightarrow \mathrm{M} 2 \rightarrow \mathrm{Y}]}\end{array}$ & $-0.03[-0.03,-0.02]$ \\
\hline $5 a$ & $\begin{array}{l}\text { Interaction between Duration of } \\
\text { Stay-Home Orders and } \\
\text { Commitment/Identification }[\mathrm{X} \times \\
\text { W] }\end{array}$ & $-0.02[-0.03,-0.006]$ \\
\hline $5 b$ & $\begin{array}{l}\text { Moderated Serial Mediation } \\
\text { Indirect Effect on Commitment } \\
\text { and Identification } \\
{[\mathrm{X} \rightarrow \mathrm{M} 1 \rightarrow \mathrm{M} 2 \times \mathrm{W} \rightarrow \mathrm{Y}]}\end{array}$ & $-0.005[-0.009,-0.001]$ \\
\hline
\end{tabular}

Notes: These analyses control for the following demographic variables (gender [male dummy], race/ethnicity [nonwhite dummy], age, education [four-year degree dummy], income [measured at wave 0]), individual differences (Big 5 personality traits, loneliness, perceived COVID-19 threat, individual COVID-19 infection [dummy]), and group-level characteristics (in-person communication time, total communication time, intimacy of interactions, group member COVID-19 infection [dummy]). All variables, except for the demographic variables and the Big 5 personality traits, are time-varying variables. All non-dummy variables are standardized. 


\section{Table 6}

Participants' Responses About Their Own Ritualistic Activities (Supplemental Data)

\begin{tabular}{|c|c|c|c|c|}
\hline Survey Question & Survey Response Options & A & $\mathrm{B}$ & $\mathrm{C}$ \\
\hline $\begin{array}{l}\text { 1. Which of the following best describes the activity? } \\
\text { The activity: }\end{array}$ & $\begin{array}{l}\text { A) Existed before the COVID-19 stay-at-home } \\
\text { orders were enacted and was not changed at all. } \\
\text { B) Existed before the COVID-19 stay-at-home } \\
\text { orders were enacted but was modified (in some } \\
\text { way) due to COVID-19. } \\
\text { C) Was invented after the COVID-19 stay-at-home } \\
\text { orders were enacted. }\end{array}$ & $10 \%$ & $47 \%$ & $43 \%$ \\
\hline $\begin{array}{l}\text { 2. Following the onset of the COVID-19 stay-at-home } \\
\text { restrictions in the United States, the activity was } \\
\text { performed: }\end{array}$ & $\begin{array}{l}\text { A) In-person only } \\
\text { B) Online only } \\
\text { C) Both in-person and online }\end{array}$ & $25 \%$ & $58 \%$ & $17 \%$ \\
\hline $\begin{array}{l}\text { 3. Did the activity involve synchronized physical } \\
\text { movements and/or utterances — such as, chanting, } \\
\text { shouting, singing? }\end{array}$ & $\begin{array}{l}\text { A) No } \\
\text { B) Sometimes } \\
\text { C) Yes }\end{array}$ & $86 \%$ & $7 \%$ & $7 \%$ \\
\hline 4. Did the activity involve consuming food or drink? & $\begin{array}{l}\text { A) No } \\
\text { B) Sometimes } \\
\text { C) Yes }\end{array}$ & $69 \%$ & $17 \%$ & $14 \%$ \\
\hline 5. To what extent was the activity social? & $\begin{array}{l}\text { A) Not at all social } \\
\text { B) Somewhat social } \\
\text { C) Very social }\end{array}$ & $12 \%$ & $47 \%$ & $41 \%$ \\
\hline 6. Would you classify the activity as a: & $\begin{array}{l}\text { A) Work meeting } \\
\text { B) Social gathering } \\
\text { C) Other }\end{array}$ & $67 \%$ & $23 \%$ & $10 \%$ \\
\hline
\end{tabular}


7. How many people participated in the activity?

A) Part of my workgroup

$21 \% \quad 79 \% \quad \mathrm{NA}$

B) All of my workgroup

8. Who created the activity?

A) Manager/supervisor

$58 \% \quad 15 \% \quad 16 \%$

B) Self

C) The workgroup

9. How often did you engage in the activity during the weeks following the onset of the COVID-19 stay-athome restrictions in the United States (e.g., March to June 2020)?

10. How important was the activity to your workgroup's identity?
A) Just once or a few times
B) Once a week
C) More than once a week

$35 \% \quad 35 \% \quad 40 \%$
A) Not at all important
B) Somewhat important
C) Very important

Notes: Because we asked participants to tell us about meaningful workplace activities, and not ritualistic activities per se, some participants recalled activities that would not meet our definition of ritual. Thus, to isolate the ritualistic activities in the dataset for this table, we filtered the data to focus on the top half of ritualistic activities (computed via median split). See Appendix C. For question number 8 (who created the activity?), additional survey response options included another peer in the workgroup (8\%) and someone outside the workgroup (3\%). 


\section{Figures}

\section{Figure 1}

The Theoretical Model

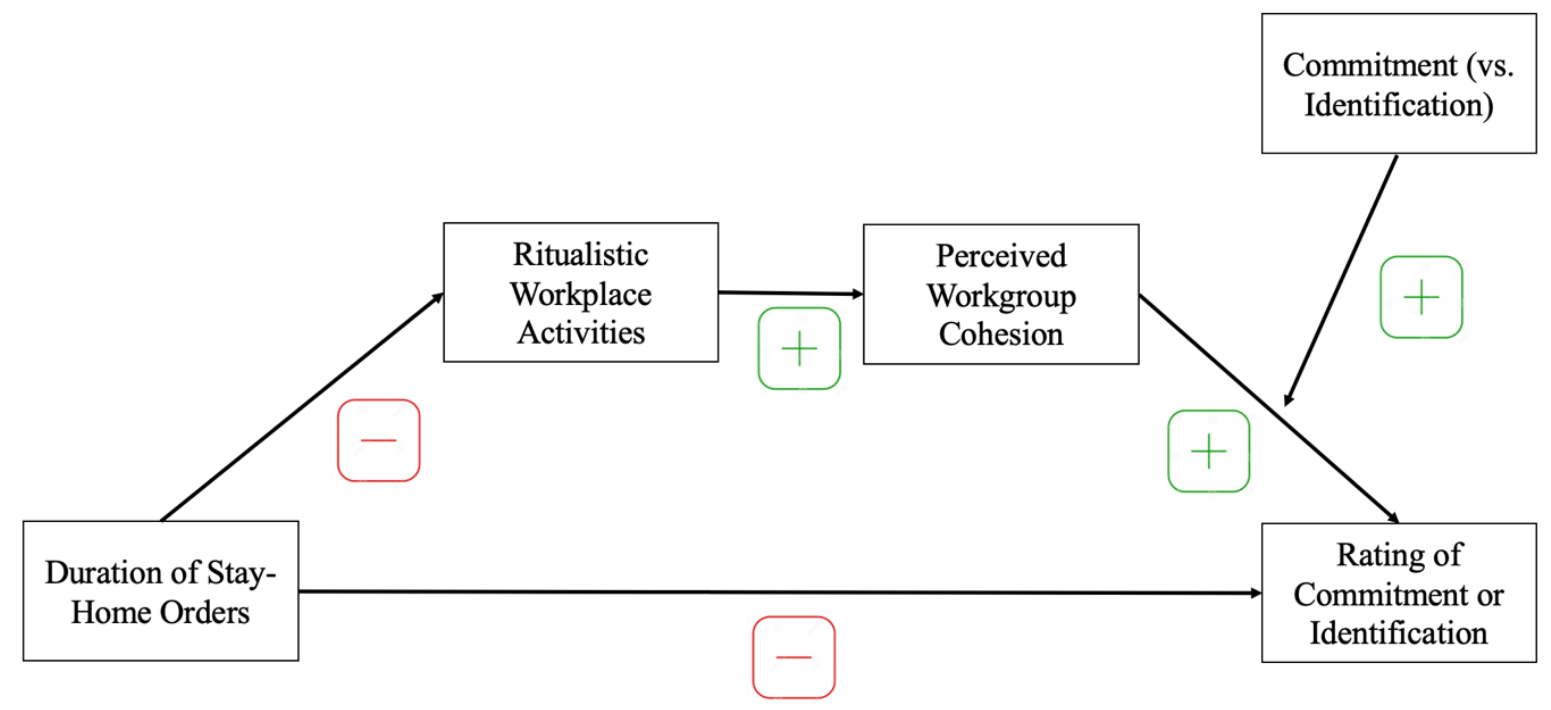




\section{Figure 2}

Workgroup Identification Measure

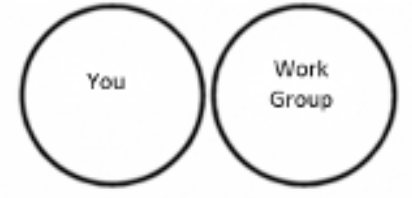

1

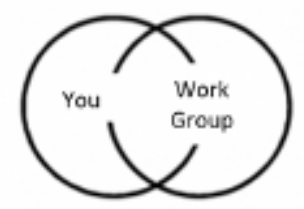

4

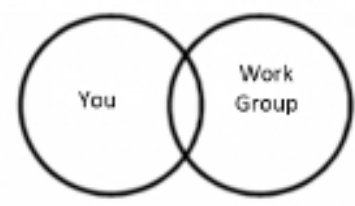

2

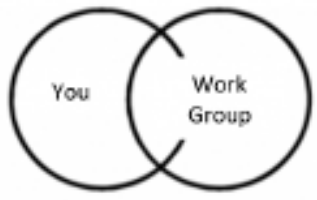

3

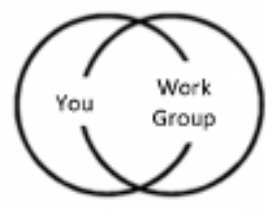

5

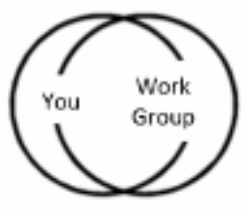

6

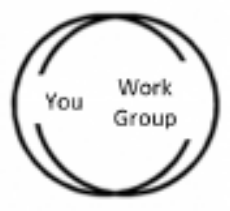

7

Notes: Wave 0 replaced "Work Group" with the letter "X." In the instructions, we told participants that "X" stands for "your work group." Bergami and Bagozzi (2000) showed this item achieved convergent validity with Mael and Ashforth's (1992) measure of identification (see also, Bartel et al., 2012; Swann et al., 2009). Moreover, the use of a visual report methodologically separates our measures of commitment and identification and thus potentially reduces common method bias (e.g., Likert-type scale and Venn diagrams) (see Podsakoff et al. 2003). 


\section{Figure 3}

The Relationship between the Duration of COVID-19 Stay-Home Orders and Standardized Ratings of Commitment and Identification

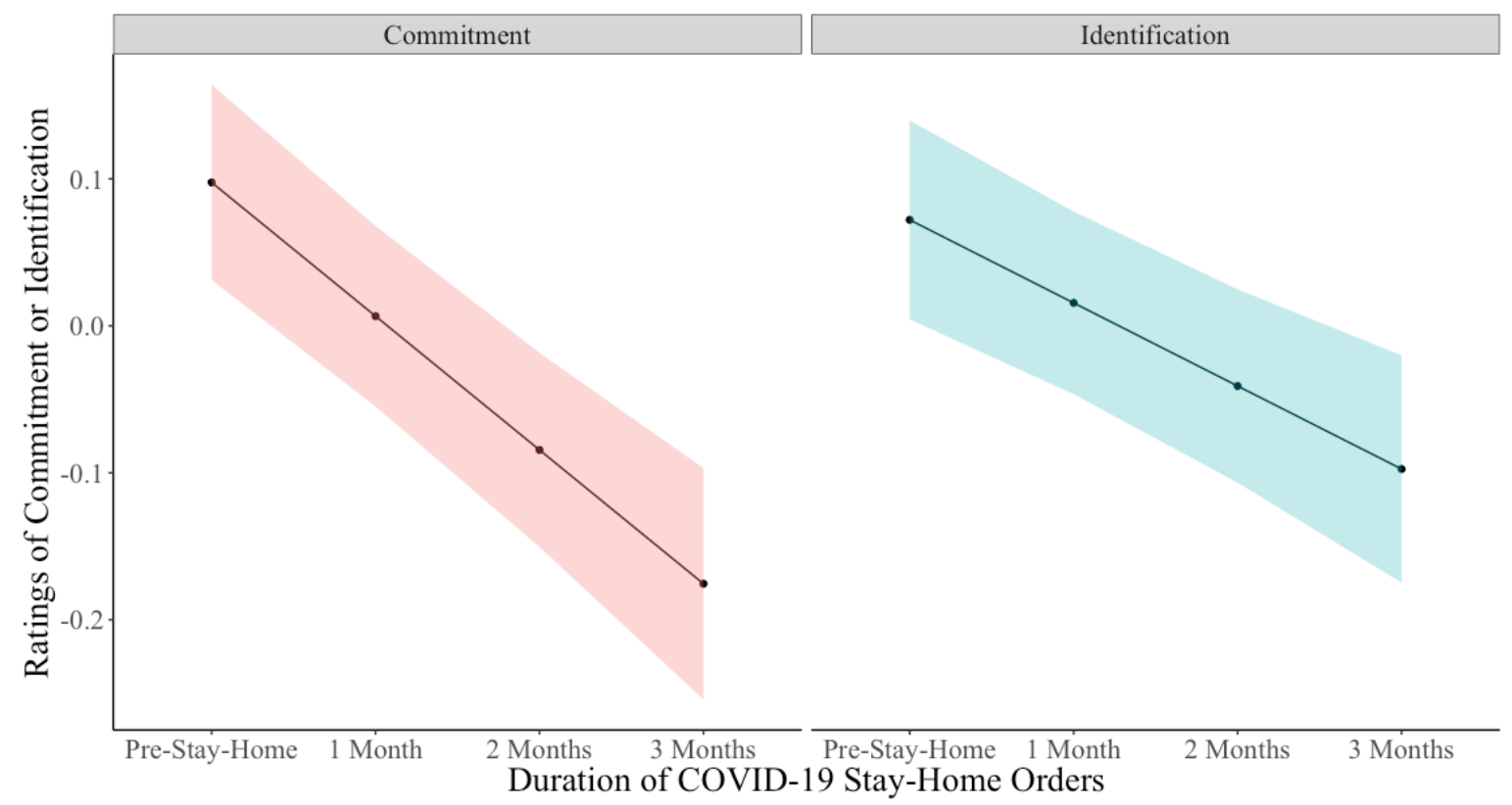

Commitment Identification

Notes: The shaded regions reflect $95 \%$ confidence interval bands. The y-axis reflects standardized ratings of commitment and identification (endpoints labeled in main text). 


\section{Figure 4}

Moderated Sequential Mediation (H5b)

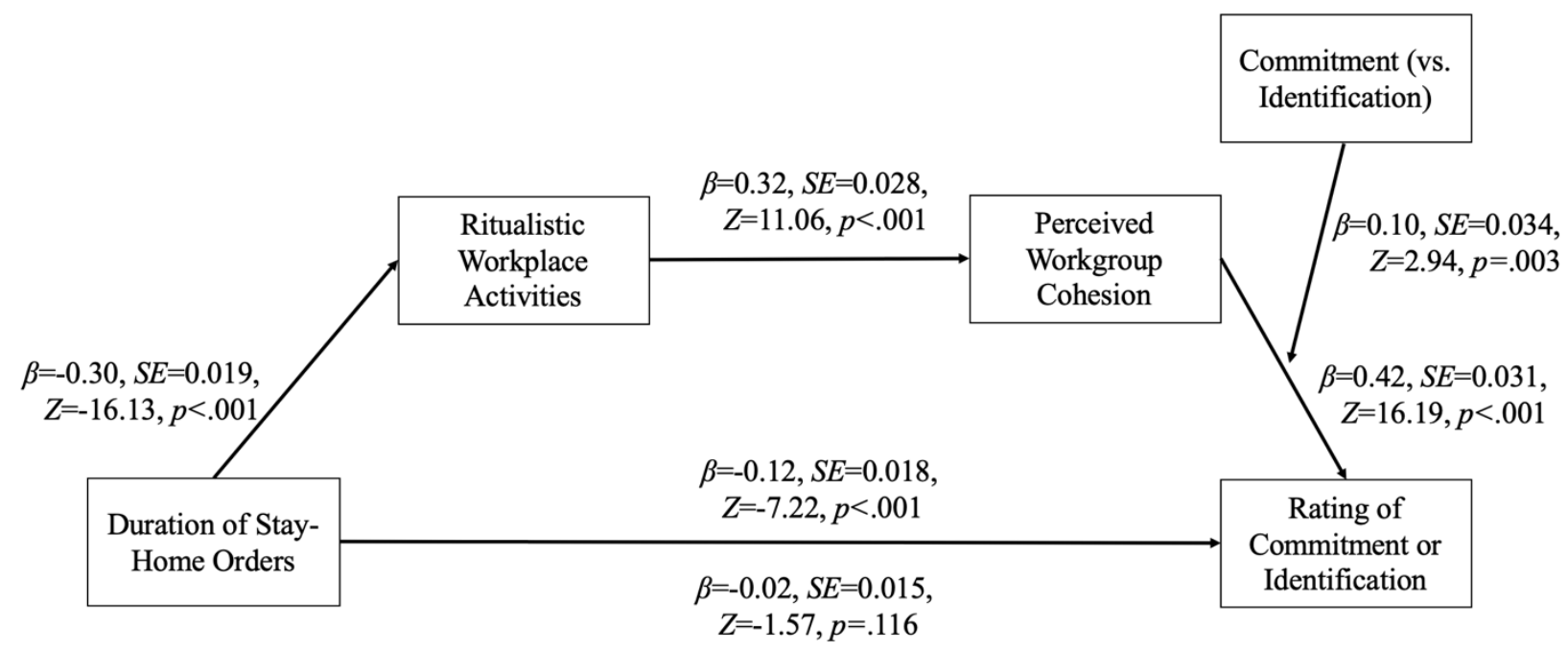

Notes: Commitment (vs. Identification) is dummy coded ("1" = commitment, " 0 " = identification). 


\section{Appendices}

\section{Appendix A: Additional Methods}

Additional sample recruitment information. We paid participants $\$ 2.50$ for completing the wave 0 survey and $\$ 2.00$ for each subsequent wave; participants received a $\$ 3.00$ bonus for completing all waves. Among the final sample $(N=772), n=454$ participated in all four waves, $n=136$ participated in three waves, $n=93$ participated in two waves, and $n=89$ participated in one wave. Moreover, when recruiting our sample of $N=1,000$ participants from Amazon Mechanical Turk, we further required that participants report that English was their native language, correctly answer two attention checks, and report being willing and able to participate in a longitudinal study.

Exclusions. We excluded 40 participants (total; 4.0\%) from our study for one of three preregistered reasons (see updated preregistration): (1) writing gibberish for the open-ended text response questions; (2) writing gibberish when writing down the names/initials of group members; or, (3) providing a large number (20+) when asked how many group members have been diagnosed with COVID-19. We ask participants to recall small groups (e.g., six people in size), so large numbers indicate a failure to follow/read the instructions. We additionally excluded 188 subjects for experiencing unstable employment during our survey window; all analyses reported in the main text are based on the remaining 772 participants. We compare the excluded sample to the final sample in Appendix B.

Changes to surveys. We modified one question after wave 1 to remove scientific jargon. Specifically, we used a slightly different wording for the ritualistic activities question in waves 0 and 1: "To what extent do you believe that this activity is a work group ritual? Rituals are 
predefined sequences of behaviors (or a single behavior) characterized by rigidity, formality, and repetition that are embedded in a larger system of symbolism and meaning."

Control variables. We collected the following variables which we control for in the "Robustness analyses" section. Since prior work has examined how negative emotions and COVID-19 threat have influenced work attitudes (e.g., Chong, Huang, \& Chang, 2020; Hu, He, \& Zhou, 2020; Trougakos, Chawla, \& McCarthy, 2020), we test whether our pathway through ritualistic activities and perceived cohesion is robust when controlling for individual differences in perceiving COVID-19 as a threat, individual and group member COVID-19 infection, and loneliness. Moreover, since workgroups that engage in more ritualistic activities might also communicate more and have more intimate interactions (e.g., Sezer et al., 2016), we control for in-person communication time (hours), total communication time (hours), and the intimacy of interactions (Likert rating) to test whether engagement in ritualistic activities uniquely predicts perceived cohesion, workgroup commitment, and workgroup identification.

Demographics. In wave 0, we collected the following demographics: age, gender, race/ethnicity, education $(1=$ Some high school or less, $2=$ High school diploma, $3=$ Some college, 4 = Two-year college degree (A.A), $5=$ Four-year college degree (B.A. or B.S.), $6=$ MA/PhD, MD, MBA, Law Degree, $7=N A)$, current income $(1=\$ 9,999$ or less, $2=\$ 10,000$ to $\$ 19,999,3=\$ 20,000$ to $\$ 29,999,4=\$ 30,000$ to $\$ 49,999,5=\$ 50,000$ to $\$ 74,999,6=\$ 75,000$ to $\$ 99,999,7=\$ 100,000$ to $\$ 200,000,8=$ Greater than $\$ 200,000)$.

Personality. In wave 0, we collected individual differences in self-reported Big 5 factors personality (TIPI; Gosling, Rentfrow, \& Swann, 2003).

Loneliness. In waves 0-3, we measured loneliness with the following three items: (1) "how often do you feel that you lack companionship?"; (2) "how often do you feel left out?"; 
and, (3) "how often do you feel isolated from others?" $(1$ = never, 5 = very often; UCLA Loneliness Scale; $\alpha=.91)$.

Perceived COVID-19 threat. In waves 1-3, we measured perceived COVID-19 threat with the following five items: (1) "Thinking about the coronavirus (COVID-19) makes me feel threatened"; (2) "I am afraid of the coronavirus (COVID-19)"; (3) "I am worried that I or people I love will get sick from the coronavirus (COVID-19)"; (4) "I am stressed around other people because I worry I'll catch the coronavirus (COVID-19)"; and, (5) "I try hard to avoid other people because I do not want to get sick" ( 1 = not at all, 5 = extremely; Conway et al., 2020; $\alpha=$ .92). To retain all data in Table 5, we inputted the average values from waves 1-3 in wave 0 .

Individual COVID-19 infection. In waves 1-3, we measured personal COVID-19 infection with the following two items: (1) "Have you been diagnosed with Coronavirus (COVID-19)?”, and (2) “Have you had coronavirus-like symptoms?” (yes/no/not sure). Participants were coded "1" if they responded "yes" to being diagnosed or having coronaviruslike symptoms and 0 otherwise.

Communication time. In waves 1-3, we asked participants to specify the number of hours they spent communicating with their work group members using each of seven communication channels (Schroeder et al., 2017): (1) “In-person conversation”; (2) “Talking back-and-forth on video (e.g., Zoom/Skype/FaceTime)"; (3) "Talking back-and-forth with voice only (e.g., a phone call)"; (4) "Writing back-and-forth with text (e.g., texting on phone, instant messaging, or email)"; (5) "Exchanging one video message at a time (e.g., through Marco Polo or WhatsApp Video)"; (6) "Exchanging one audio message at a time (e.g., WhatsApp voice note)"; and, (7) "Other" with a textbox provided. The first question (in-person conversation) constituted our measure of in-person communication time. To compute total communication time, we summed 
the responses across the seven methods to yield the total number of hours communicating. In wave 0 , we used a different measure for communication time, asking participants to report the percent of time they communicated with seven communication mediums: "Prior to the COVID19 pandemic, what percentage of total time spent communicating with work group members used the following platforms? Your answers should sum to $100 \%$." As we did not ask for the raw number of hours in wave 0 , we were unable to incorporate this measure in our analyses. To retain all data in Table 5, we inputted the average values from waves 1-3 in wave 0.

Intimate interactions. In waves 2-3, we measured the perceived intimacy of group conversations using the following item, "In the last week, how connected and close were your interactions with your work group?" ( $1=$ not at all, $5=$ extremely). In waves 0 and 1 , we used a slightly different wording for the intimacy question: "how intimate were your interactions with your work group?"

Group member COVID-19 infection. We measured group member COVID-19 infection with the following two items: (1) "How many, if any, members of this work group have been diagnosed with Coronavirus (COVID-19)?”, and (2) “How many, if any, members of your work group have had coronavirus-like symptoms?" Participants were coded "1" if they responded 1 person or more was diagnosed or had coronavirus-like symptoms and 0 otherwise.

Additional measures. The surveys collected additional measures, which were either outside the scope of this paper or only measured in one survey wave (thus not permitting withinperson analyses). In addition to asking participants about the status of their workgroups during the onset of the pandemic, we also asked participants about the status of their families and friends. The full surveys are available on the Open Science Framework (https://osf.io/g6nua/?view_only=f79a6b5037ad49378ca986675a1bbd1b). 


\section{Appendix B: Additional Results}

How do employees with stable employment compare with employees whose

employment is unstable? In the main text, we excluded "unstable employees" $(N=188)$ who indicated they were not "Working for SAME company as prior to COVID-19 pandemic" in all the waves they participated. Thus, our sample reported in the main text $(N=772)$ consisted of "stable employees." Because unstable employees were facing job termination in the midst of a global pandemic, it is unsurprising that the duration of Stay-Home orders in effect over time were associated with a larger decrease in unstable employees' workgroup commitment, $\beta=$ $0.25, \mathrm{SE}(\beta)=0.03, t(765.60)=-9.85, p<.001$, than stable employees' workgroup commitment, $\beta=-0.09, \operatorname{SE}(\beta)=0.01, t(780.84)=-6.80, p<.001$ (interaction: $\beta=0.16, \operatorname{SE}(\beta)=0.03, t(768.89)$ $=5.66, p<.001)$. Thus, our focus on stable employees during the onset of Stay-Home orders provides a conservative test of our hypotheses.

Are our results robust to a different specification of ritualistic activities? In the main text, we operationalized ritualistic activities by averaging participants' responses to the 5-point ritual Likert questions. Here, we report an additional specification: the number of activities they listed ("number of rituals"; range: 0-3). Replicating $\mathrm{H} 1$ and $\mathrm{H} 2$, there was a negative relationship between duration of Stay-Home orders and ritualistic activities $(\mathrm{H} 1 ; \beta=-0.36, \mathrm{SE}(\beta)=0.02$, $t(812.15)=-21.83, p<.001)$ and a positive relationship between ritualistic activities and perceived cohesion $(\mathrm{H} 2 ; \beta=0.19, \mathrm{SE}(\beta)=0.02, t(452.27)=12.05, p<.001)$. Moreover, the $95 \%$ CI for the index of sequential mediation $(\mathrm{H} 4 \mathrm{~b})$ and moderated serial mediation (H5b) did not include zero, indicating a significant serial mediation effect and moderated serial mediation effect, respectively (H4b, Index of Serial Mediation 95\% CI [-0.040, -0.023]; H5b, Index of 
Moderated Serial Mediation 95\% CI [-0.016, -0.002]). Overall, these results indicate that our results are robust to an alternate specification of ritualistic activities.

\section{What are the relationships between duration of Stay-Home order in effect over time}

and other potential mediator variables? In contrast to the decline in ritualistic activities, workgroup cohesion and workgroup commitment and identification, the duration of Stay-Home orders was associated with more in-person communication, $\beta=0.02, \mathrm{SE}(\beta)=0.01, t(1712)=$ $1.82, p=.068$, more total communication time, $\beta=0.07, \operatorname{SE}(\beta)=0.01, t(1436)=5.45, p<.001$, and more intimate interactions, $\beta=0.14, \mathrm{SE}(\beta)=0.01, t(661.16)=9.68, p<.001$. Moreover, duration of Stay-Home orders was associated with less perceived COVID-19 threat, $\beta=-0.05$, $\operatorname{SE}(\beta)=0.01, t(1670)=-6.81, p<.001$, indicating that increasing threat (and associated emotions, such as anxiety) are not responsible for the decline in workgroup commitment. Altogether, these results indicate that employees were able to adjust to some of the workgroup challenges posed by the Stay-Home orders (e.g., evidenced by increased intimacy of interactions and decreased perception of COVID-19 threat) as the duration of Stay-Home orders increased. However, as our results in the main text show, employees were not able to accommodate ritualistic activities, resulting in decreased workgroup commitment.

\section{Appendix C: Supplemental Data}

Appendix C reports the full details for the supplemental data collection. The survey was preregistered on AsPredicted (https://aspredicted.org/blind.php?x=ji3hf3).

Participants. We predetermined our sample size to target 200 participants. To participate, we required that potential participants work full-time for the same organization, with the same workgroup, without disruption (i.e., not furloughed) from January 2020 to the present 
day (January 2021). In total, 203 adults from the U.S. on Prolific Academic (121 male, 82 female; $\left.M_{\text {age }}=35.49, S D_{\text {age }}=9.62\right)$ completed the study in return for $\$ 1.60$.

Procedure. We asked participants to recall a meaningful activity shared with their workgroup: "Please think about a specific meaningful activity your workgroup did together during the weeks following the onset of the COVID-19 stay-at-home restrictions in the United States (e.g., March to June 2020). The activity can be in-person or remote/virtual." We asked participants to elaborate on the activity with a writing prompt (e.g., What was the activity? Who participated in the activity?). Participants then completed our self-report questionnaire (details below).

\section{Materials (Survey)}

Engagement in ritualistic activities. As in the main survey, we asked participants "To what extent do you consider this activity to be ritualistic? Ritualistic workplace activities symbolize group values and tend to be done multiple times in the same specific way each time" $(1=$ not at all ritualistic, $7=$ very ritualistic $)$. To augment this measure, we also asked participants the following three-item ritual scale: "To what extent" (1) "is the activity done in the same specific way each time?", (2) "is the activity meaningful to you?", (3) "does the activity symbolize your workgroup values?" $(1=$ not at all, $7=$ very $m u c h ; \alpha=.59)$. As preregistered, we standardized the single-item and three-item measures and averaged them together to yield a standardized ritualism index. While we used a 5-point Likert scale in the longitudinal survey, we opted for a 7-point Likert scale in the cross-sectional replication to increase variation in responses.

Characteristics of ritualistic workplace activities. To conceptualize ritualistic activities, we asked participants the following questions: (1) "Which of the following best describes the 
activity": (a) "The activity existed before the COVID-19 stay-at-home orders were enacted and was not changed at all," (b) "The activity existed before the COVID-19 stay-at-home orders were enacted but was modified (in some way) due to COVID-19," (c) "The activity was invented after the COVID-19 stay-at-home orders were enacted"; (2) "Following the onset of the COVID19 stay-at-home restrictions in the United States, the activity was performed": (a) "In-person only," (b) "Online only," (c) "Both in-person and online"; (3) "Did the activity involve synchronized physical movements and/or utterances—-such as, chanting, shouting, singing": (a) "No," (b) "Sometimes," (c) "Yes"; (4) "Did the activity involve consuming food or drink": (a) “No," (b) "Sometimes," (c) "Yes"; (5) "To what extent was the activity social”: (a) "Not at all social," (b) "Somewhat social," (c) "Very social”; (6) "Would you classify the activity as a": (1) “Work meeting," (b) “Social gathering (e.g., happy hour, lunch, party),” (c) Other (please describe)"; (7) "How many people participated in the activity": (a) "Part of my workgroup," (b) "All of my workgroup"; (8) "Who created the activity": (a) "Manager/supervisor," (b) "I did," (c) "The workgroup," (d) "Another peer in the workgroup," (e) "Someone outside the workgroup," (f) "Other"; (8) "How often did you engage in the activity during the weeks following the onset of the COVID-19 stay-at-home restrictions in the United States (e.g., March to June 2020)": (a) Just once, (b) “A few times," (c) “Once a week," (d) "More than once a week"; (9) "How important was the activity to your workgroup's identity": (a) "Not at all important," (b) "Somewhat important," (c) "Very important."

Perceived cohesion. We asked participants to rate the perceived cohesion of the workgroup "after participating in the activity" using the same six-item scale reported in the main study $(1=$ not at all, $7=$ very much; Denson et al., 2006; $\alpha=.84)$. 
Workgroup commitment. We asked participants to rate their commitment to the workgroup "after participating in the activity" using the same four-item scale reported in the main study $(1$ = not at all, 7 = very much; adapted from Klein et al., 2014, Roccas et al., 2008; $\alpha$ $=.94)$.

Workgroup identification. We asked participants to rate their identification to the workgroup "after participating in the activity" using a modified version of Mael and Ashforth's (1992) Likert scale: (1) "If someone were to criticize this workgroup, it would feel like a personal insult to me"; (2) "When I talked about this workgroup, I would say 'we' rather than 'they"; (3) "This workgroup's successes were my successes"; (4) "If someone praised this workgroup, it would feel like a personal compliment to me"; (5) "If a story in the media criticized this workgroup, I would feel embarrassed" ( 1 = not at all, $7=$ very much; $\alpha=.84)$.

\section{Results and Discussion}

As predicted, and consistent with the main study reported in the main paper, engagement in ritualistic activities (ritualism index) was positively related to perceived workgroup cohesion $(\mathrm{H} 2), \beta=0.32, \mathrm{SE}(\beta)=0.07, t(201)=4.76, p<.001$, and perceived workgroup cohesion was positively related to workgroup commitment $(\mathrm{H} 3), \beta=0.70, \mathrm{SE}(\beta)=0.06, t(201)=11.23, p<$ .001. Providing support for H4b, workgroup commitment and identification showed differential associations with perceived workgroup cohesion, as evidenced by a significant interaction between perceived cohesion and standardized ratings of commitment and identification, $\beta=0.17$, $\operatorname{SE}(\beta)=0.05, t(201)=3.18, p<.001$. Decomposing the interaction revealed the association between perceived workgroup cohesion and commitment, $\beta=0.62, \mathrm{SE}(\beta)=0.06, t(302)=10.47$, $p<.001$, was stronger than the association between perceived workgroup cohesion and identification, $\beta=0.45, \mathrm{SE}(\beta)=0.06, t(302)=7.54, p<.001$. 
Moreover, further supporting $\mathrm{H} 5 \mathrm{~b}$, in a moderated mediation model ( $\mathrm{X}=$ ritualistic activities, $\mathrm{M}=$ perceived cohesion, $\mathrm{W}=$ commitment or identification, $\mathrm{Y}=$ standardized ratings of commitment or identification), the $95 \%$ CI for the index of moderated mediation did not include zero, indicating commitment versus identification moderated the mediation effect of perceived cohesion (Index of Moderated Mediation $=0.055, S E=0.021,95 \%$ CI [0.013, 0.097]). Perceived cohesion more strongly mediated the relationship between engagement in ritualistic activities and workgroup commitment (Indirect Effect $=0.176, S E=0.048,95 \%$ CI $[0.082$, 0.270]) than the relationship between engagement in ritualistic activities and workgroup identification $($ Indirect Effect $=0.121, S E=0.038,95 \%$ CI $[0.046,0.196])$.

This replication, using a different measure of identification, supports our theory and bolsters our findings that perceived workgroup cohesiveness influences workgroup commitment more than workgroup identification. Moreover, these results provide more insight about the nature of ritualistic workplace activities in workgroups (see Table 6). 